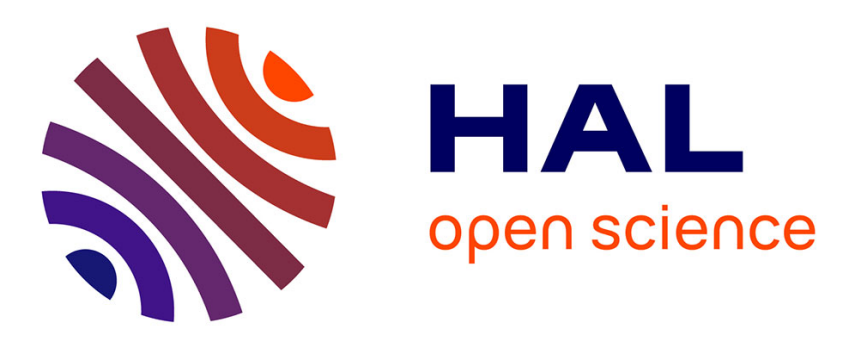

\title{
Device-specific evaluation of intraventricular left ventricular assist device position by quantitative coaxiality analysis.
}

Amedeo Anselmi, Sophie Collin, Pascal Haigron, Jean-Philippe Verhoye, Erwan Flecher

\section{To cite this version:}

Amedeo Anselmi, Sophie Collin, Pascal Haigron, Jean-Philippe Verhoye, Erwan Flecher. Devicespecific evaluation of intraventricular left ventricular assist device position by quantitative coaxiality analysis.. Journal of Surgical Research, 2017, 213, pp.110-114. 10.1016/j.jss.2017.02.027 . hal01508419

HAL Id: hal-01508419

https://hal-univ-rennes1.archives-ouvertes.fr/hal-01508419

Submitted on 5 Jul 2017

HAL is a multi-disciplinary open access archive for the deposit and dissemination of scientific research documents, whether they are published or not. The documents may come from teaching and research institutions in France or abroad, or from public or private research centers.
L'archive ouverte pluridisciplinaire HAL, est destinée au dépôt et à la diffusion de documents scientifiques de niveau recherche, publiés ou non, émanant des établissements d'enseignement et de recherche français ou étrangers, des laboratoires publics ou privés. 


\title{
DEVICE-SPECIFIC EVALUATION OF INTRAVENTRICULAR LVAD POSITION BY QUANTITATIVE COAXIALITY ANALYSIS
}

Short title: Assessment of LVAD position

\author{
Amedeo ANSELMI ${ }^{1,2,3}$, MD PhDs, Sophie COLLIN ${ }^{1,2,4}$, Pascal \\ HAIGRON $^{1,2}, \mathrm{PhD}$, Jean-Philippe VERHOYE ${ }^{1,2,3}, \mathrm{MD}$ PhD, Erwan \\ FLECHER $^{1,2,3}$, MD PhD
}

\author{
${ }^{1}$ INSERM U1099, Rennes, F-35000, France \\ ${ }^{2}$ Université de Rennes 1, LTSI, Rennes, F-35000 France \\ ${ }^{3} \mathrm{CHU}$ Rennes, Division of Thoracic and Cardiovascular Surgery, Rennes, F-35000, \\ France \\ ${ }^{4}$ ANSYS, Villeurbanne F-69100, France
}

Address for correspondence:

Amedeo Anselmi, MD PhDs

Division of Thoracic and Cardiovascular Surgery

CHU de Rennes

2, rue Henri le Guilloux, 35033 Rennes cedex, France

Tel\# 0033(0)637060379

Fax\# 0033(0)299282497

Email: amedeo.anselmi@alice.it

TEXT WORD COUNT: 1,098

ABSTRACT WORD COUNT: 237

Authors' contribution.

Conception and design, data collection and analysis: AA, SC, EF

Writing the paper, critical revision: AA, SC

Final approval: PH, JPV, EF

Sources of Funding: 'Association Ouest Transplant' (Western French Transplantation Association) (partial financial support). 


\section{Abstract}

Background. Patient-specific anatomy may influence the final intraventricular positioning of inflow cannula in left ventricular assist device (LVAD) recipients. An association exists between such positioning and clinical outcomes (specifically, orientation towards the interventricular septum - IVS - has negative prognostic implications). Alternative commercially available LVADs are characterized by markedly different design, with potential consequences on intrathoracic fitting among individual patients.

Material and Methods. A cohort of 13 LVAD recipients (either HeartMate II - Group A or Jarvik 2000 Flowmaker - Group B) was evaluated. On postoperative CT-scans, we reconstructed the implanted LVAD (semiautomatic segmentation), defined the target mitral orifice (3D Slicer software) and built a coordinate system to quantify the coaxiality of the cannula with the mitral valve axis (angles $\varphi$ and $\theta$, expressed as percentage variation from the ideal value $\varphi=\theta=0$ ).

Results. Group A presented significantly greater average percentage variation of the $\varphi$ angle (significantly greater orientation of the intraventricular cannula towards the IVS) $(33.2 \% \pm 32.1$ vs. $1.9 \% \pm 0.9, p=0.001)$. Group A presented significantly greater average percentage variation of the $\theta$ angle $(52.7 \% \pm 23.6$ vs. $14.5 \% \pm 6.3, p=0.013)$.

Conclusions. The device assessed in Group B showed in the present series better average coaxiality with the mitral orifice. Such finding is related with its design (total intraventricular placement) and interaction with thoracic structures. The present method is being integrated in the development of LVAD virtual implantation tools, and may help physicians in patient-specific selection among alternative devices.

KEY WORDS: Left Ventricular Assist Device; Computer-assisted surgery; Preoperative simulation 


\section{Introduction.}

Left Ventricular Assist Device (LVADs) are increasingly used for the treatment of advanced heart failure (HF), with significant improvement of survival and quality-oflife in appropriately selected patients [1, 2]. Nonetheless, LVAD therapy remains associated with noteworthy rates of early and late complications. Thrombotic and thromboembolic events are particularly dreadful; the risk of stroke is about $20 \%$ after 2 years on LVAD support in the INTERMACS Registry [3]. Although thromboembolic events under LVAD therapy are of multifactorial origin, the underlying mechanisms are not fully understood [4].

Recently, we have suggested that further insights into this issue can be obtained through analysis of postoperative CT scan of LVAD recipients, based on computer segmentation and three-dimensional reconstruction $[5,6]$. Indeed, we found a relationship between suboptimal intraventricular inflow cannula positioning and adverse events at follow-up [5]. Such approach is ultimately intended at assisting the physicians, not only in the 'customization' of implantation technique and late management, but also in the decision-making among different devices in individual patients. Herein we propose the use of a software tool developed by our team to describe device-specific features of intraventricular LVAD positioning. 


\section{Methods and Results.}

As previously described [5], the present investigation was performed by a multidisciplinary team including senior cardiac surgeons and experts in biomedical engineering and image processing for innovative applications [7]. We retrospectively identified LVAD recipients at our Institution, who had postoperative contrastenhanced ECG-gated CT scan. The indication to LVAD, the early and late management were conducted according to the current recommendations [8]. Implanted devices were the HeartMate II LVAD (Thoratec Corporation, Pleasanton, CA) and the Jarvik 2000 Flowmaker (Jarvik Heart Inc. New York, NY). The choice among alternative devices was based on patients' characteristics and type of LVAD employment (permanent implantation or so called destination therapy vs. bridge-totransplantation). Generally, minimal or no conflict with left ventricular (LV) inner walls (namely, the interventricular septum - IVS) and coaxiality of the LVAD inflow cannula with the mitral valvular orifice are considered as the main anatomical requirements. Hence, we performed an analysis of coaxiality (3D Slicer software ver. 4.4.0 [9]). The native mitral annulus was identified by the user (a cardiac surgeon with experience in heart failure management) through a series of 12-to-20 points within a representation of post-implantation CT scans (Figure 1A). The software interface then provides an ovoid corresponding to the mitral orifice and passing through the average plane defined by the center of the mitral orifice and the above series of points (Figure 1B). A coordinate system was built; it was defined by the center of the mitral orifice and three perpendicular axes $x, y$ and $z$. The latero-lateral axis $x$ was on the mitral plane and was defined by the center of the orifice and the point corresponding to the anterior mitral commissure. The anterior-posterior axis y was also on the mitral plane and was defined as the perpendicular to the $x$ axis. The $z$ axis was perpendicular to 
the mitral plane at its center. Semi-automatic segmentation was used to obtain the intraventricular LVAD inflow cannula and its axis. The cannula axis orientation was defined in spherical-like coordinates by the $\varphi$ angle (representing its orientation towards either the lateral LV wall or the IVS) and the $\theta$ angle (representing its orientation with respect to the anterior or inferior LV wall) (Figure 1C). The ideal angle value being $\varphi=\theta=0^{\circ}$ (perfect coaxiality with the $z$ axis), the resul ts were expressed as percentage variation from this ideal value within a range of $\pm 90^{\circ}$ (i.e., $\varphi=0^{\circ}$ is expressed as $0 \%$ variation and $\varphi=90^{\circ}$ is expressed as $100 \%$ variation). Institutional approval of this research was obtained.

Herein, the postoperative CT-scans of thirteen LVAD recipients were analyzed. Patients were divided into subgroups according to the LVAD model (Group A: HeartMate II LVAD, 10 patients; Group B: Jarvik 2000 Flowmaker, 3 patients). Data were analyzed using SPSS software ver. 19.0 (SPSS, Chicago, IL), and presented as mean \pm standard deviation (continuous variables). Intergroup comparison was achieved through the Mann-Whitney $U$ test (alpha level: 0.05). Since this study was retrospective and no additional diagnostic or therapeutic procedure than standard clinical management has been performed, individual patients' consent to enter the study was waived.

Table 1 reports individual patients' results. Average percentage variation of $\varphi$ angle was significantly greater in Group A vs. Group B $(33.2 \% \pm 32.1$ vs. $1.9 \% \pm 0.9$, $p=0.014)$. In Group A, 9 out of 10 patients presented $\varphi$ rotation of the cannula axis towards the IVS, and only one towards the lateral LV wall (average rotation towards the IVS in Group A: $36.1 \% \pm 32.7$ ). In Group B, only one patient presented a limited $\varphi$ 
rotation towards the IVS $(2.8 \%)$. Average percentage variation of $\theta$ angle was significantly greater in Group A vs. Group B $(52.7 \% \pm 23.6$ vs. $14.5 \% \pm 6.3, p=0.028)$.

\section{Discussion.}

The present data indicate that unique design features of alternative commercially available LVADs may play a role in the determinism of intraventricular inflow cannula positioning in closed chest conditions. Previously, qualitative analysis studies put the intraventricular LVAD cannula deviation towards the IVS and malalignment with the mitral orifice in perspective with an increased risk of clinical adverse events (thromboembolism and device dysfunction) [10]. Disturbed blood drainage and intracavitary stasis are potential subtending mechanisms. Conventional X-rays can provide a qualitative appreciation of the cannula orientation (Figure 3); yet, patientspecific variability in the orientation of the mitral valve and in left ventricular morphology render this approach severely limited. Recently, we developed an interactive software-based method for quantitative assessment of LVAD inflow cannula orientation; initial results suggested the potential to predict adverse events (namely, thromboembolic events) through such approach [5]. Despite common general principles (magnetically-levitated, continuous-flow pumps with inflow within the LV, outflow usually at the ascending aorta), commercially available LVAD models greatly vary in size and design. The Jarvik 2000 device is characterized by the inclusion of the blood impeller within the intraventricular inflow portion; therefore, the outflow Dacron graft is the sole extraventricular portion of the device (Figure 2A and B). Such design minimizes conflict between the pump body and the chest wall (Figure 2C). Indeed, thoracic wall conflict has been suggested to explain migration of 
the intraventricular inflow cannula from the intended orientation after chest closure, despite satisfactory orientation in open chest conditions [11]. This mechanism probably explains the significantly better mitral alignment for all angles in Group B. Concordantly, the present project also involved the development of virtual implantation and simulation of conflict between alternative LVADs and the thoracic wall. Herein, $50 \%$ of Group A patients and $33 \%$ of Group B patients presented at least one complication at follow-up (among pump thrombosis, pump dysfunction, stroke or TIA). Larger investigations are needed to provide insights into the relationship between cannula orientation and clinical outcomes at follow-up. Similarly, our data are insufficient to propose orientation cutoff values for subsequent clinical interpretation.

$3 \mathrm{D}$ echocardiography imaging is probably to play an expanding role in LVAD evaluation. Nonetheless, with respect to cannula orientation assessment and LVAD virtual implantation, CT scan provides information about surrounding structures (i.e. chest wall), is not operator-dependent and images can be reliably elaborated through segmentation. Conversely, echocardiography does not entail irradiation or contrast agent injection.

In conclusion, the presented method allows to measure in a refined way the intraventricular positioning of LVADs, and allows fit assessment of alternative LVAD models. It is being employed for the development of LVAD virtual implantation [6]. Hence, patient-specific factors (i.e., chest morphology, size and orientation of cardiac chambers) can be considered to optimize device selection/positioning and, therefore, clinical results. Device choice is based on a multitude of considerations, and the present research may provide additional useful criteria. Given the growing number of novel LVADs which are currently in advanced or early development phase, virtual 
evaluation may acquire greater importance for both the prototyping and the preclinical evaluation phases.

\section{Acknowledgements}

Sources of Funding: 'Association Ouest Transplant' (Western French Transplantation Association) (partial financial support).

This work has been partially conducted in the experimental platform TherA-Image (Rennes, France) supported by Europe FEDER.

\section{Conflicts of interest}

None. 


\section{References}

1. Estep JD, Starling RC, Horstmanshof DA et al. Risk Assessment and Comparative Effectiveness of Left Ventricular Assist Device and Medical Management in Ambulatory Heart Failure Patients: Results From the ROADMAP Study. J Am Coll Cardiol. 2015;66:1747-61.

2. Rose EA, Gelijns AC, Moskowitz AJ et al. Long-term use of a left ventricular assist device for end-stage heart failure. N Engl J Med. 2001;345:1435-43.

3. Kirklin JK, Naftel DC, Kormos RL et al. Fifth INTERMACS annual report: risk factor analysis from more than 6,000 mechanical circulatory support patients. J Heart Lung Transplant. 2013;32:141-56.

4. Blitz A. Pump thrombosis-A riddle wrapped in a mystery inside an enigma. Ann Cardiothorac Surg. 2014;3:450-71.

5. Anselmi A, Collin S, Haigron P, Verhoye JP, Flecher E. Virtual implantation and patient-specific simulation for optimization of outcomes in ventricular assist device recipients. Med Hypotheses. 2016;91:67-72.

6. Anselmi A, Collin S, Haigron P, Verhoye JP, Flecher E. Virtual implantation of a novel LVAD: toward computer-assisted surgery for heart failure. J Surg Res. 2016;205:204-7.

7. Haigron P, Dillenseger JL, Luo L, Coatrieux JL. Image-guided therapy: evolution and breakthrough. IEEE Eng Med Biol Mag. 2010;29:100-4.

8. Feldman D, Pamboukian SV, Teuteberg JJ et al. The 2013 International Society for Heart and Lung Transplantation Guidelines for mechanical circulatory support: executive summary. J Heart Lung Transplant. 2013;32:157-87. 
9. Fedorov A, Beichel R, Kalpathy-Cramer $\mathrm{J}$ et al. 3D Slicer as an image computing platform for the Quantitative Imaging Network. Magn Reson Imaging. 2012;30:1323-41.

10.Taghavi S, Ward C, Jayarajan SN, Gaughan J, Wilson LM, Mangi AA. Surgical technique influences HeartMate II left ventricular assist device thrombosis. Ann Thorac Surg.;96:1259-65.

11.Kazui T, Bierhals A, Zhang A et al. Abstract 20215: Left Ventricular Assist Device Inflow Cannula Mitral Alignment and Pump Migration Impact LVAD Dysfunction Over Long Term Support. Circulation. 2014; 130: A20215. 


\section{Figure Legends}

Figure 1. A. Representation of post-implantation CT scan and identification by the user of the contour of the mitral valvular annulus (screenshot of a dedicated software tool). B. Three-dimensional representation of the cardiac chambers after segmentation, of the target mitral valvular orifice with coordinates system and of an implanted Jarvik 2000 LVAD. C. Detail of the coordinates system for analysis of LVAD inflow cannula orientation. The angles $\theta$ and $\varphi$ describe the deviation of the inflow cannula axis with respect to the ideal orientation.

Figure 2. A. Photo of a Jarvik 2000 Flowmaker device; the pump body and the outflow Dacron graft are evident. After implantation, the pump lies entirely within the LV cavity and corresponds to the inflow portion of the device. B. CBCT (Cone-Beam Computed Tomography) acquisition of the device. C. 3D mesh representation of a Jarvik 2000 Flowmaker. D. Analysis of LVAD interaction with the thoracic wall in closed chest conditions: reconstruction showing minimal interaction between the pump body and the thoracic wall and preservation of adequate LVAD orientation.

Figure 3. Face chest X-rays from a Group A patient (A) and a Group B patient (B). 
Table 1. Details of LVAD inflow cannula orientation (individual patients' $\theta$ and $\varphi$ angles, and percentage deviation from ideal values).

\begin{tabular}{|l|l|l|}
\hline Patient & Angles & Percentage deviation \\
\hline P1 (Group A) & $\theta=+49.79$ & $55.3 \%$ \\
& $\varphi=-9.98$ & $11.1 \%$ \\
\hline P2 (Group A) & $\theta=-41.17$ & $45.7 \%$ \\
& $\varphi=-82.54$ & $91.7 \%$ \\
\hline P3 (Group A) & $\theta=+37.47$ & $41.6 \%$ \\
& $\varphi=-9.74$ & $10.8 \%$ \\
\hline P4 (Group A) & $\theta=+53.76$ & $59.7 \%$ \\
& $\varphi=-2.36$ & $2.6 \%$ \\
\hline P5 (Group A) & $\theta=+72.4$ & $80.4 \%$ \\
& $\varphi=-35.98$ & $40 \%$ \\
\hline P6 (Group A) & $\theta=+82.56$ & $91.7 \%$ \\
& $\varphi=-32.09$ & $35.7 \%$ \\
\hline P7 (Group A) & $\theta=+78.48$ & $87.2 \%$ \\
& $\varphi=+24.04$ & $26.7 \%$ \\
\hline P8 (Group A) & $\theta=+51.7$ & $57.4 \%$ \\
& $\varphi=-13.54$ & $15 \%$ \\
\hline P9 (Group A) & $\theta=+51.78$ & $57.5 \%$ \\
& $\varphi=+6.86$ & $7.6 \%$ \\
\hline P10 (Group A) & $\theta=+9.66$ & $10.7 \%$ \\
& $\varphi=-27.6$ & $30.7 \%$ \\
\hline P11 (Group B) & $\theta=-12.02$ & $13.4 \%$ \\
\hline P12 (Group B) & $\theta=+1.49$ & $1.7 \%$ \\
\hline P13 (Group B) & $\theta=-19.2$ & $8.8 \%$ \\
& $\varphi=+1.02$ & $2.8 \%$ \\
\hline
\end{tabular}



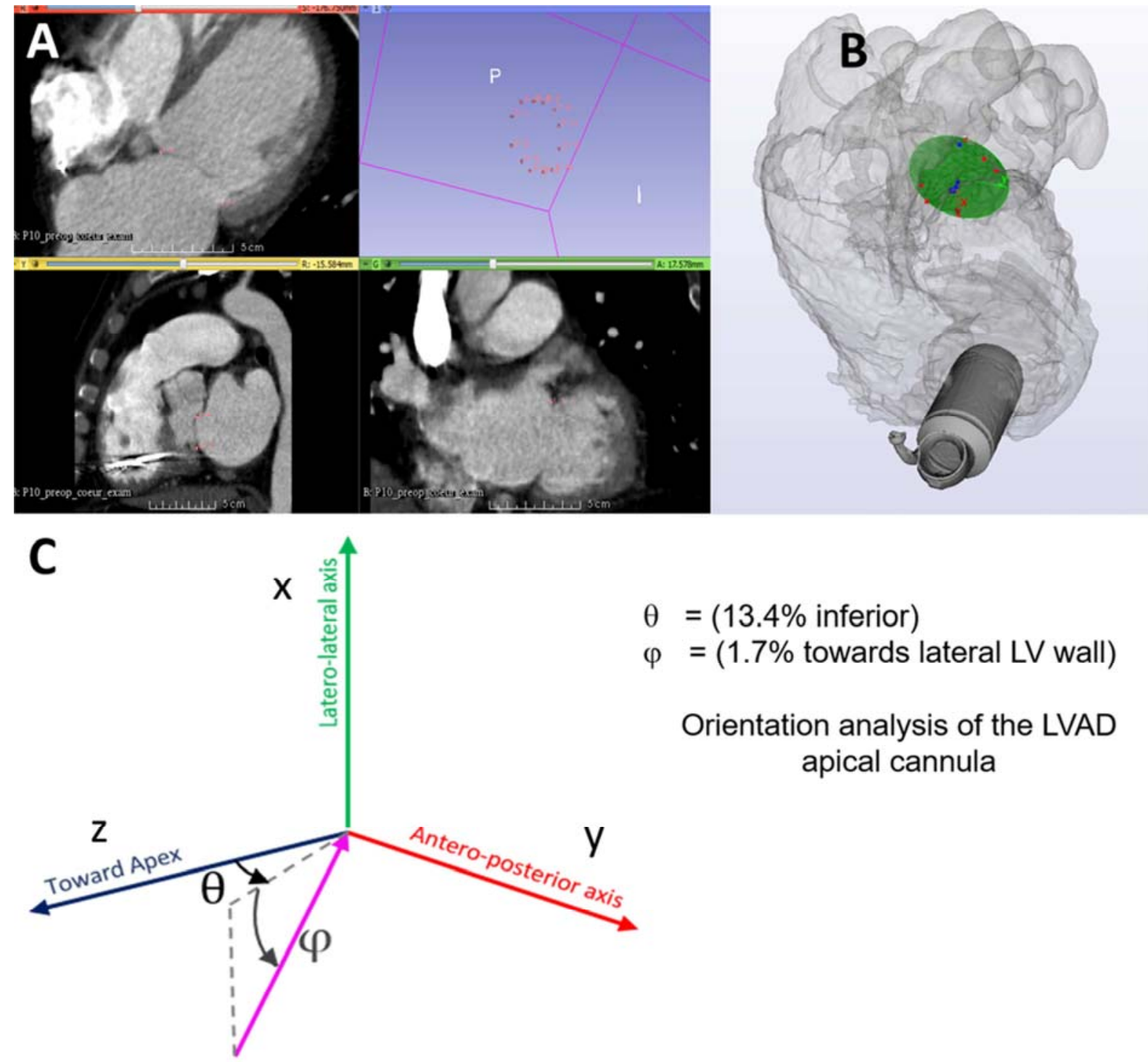

$\theta=(13.4 \%$ inferior $)$

$\varphi=(1.7 \%$ towards lateral $\mathrm{LV}$ wall $)$

Orientation analysis of the LVAD apical cannula 


\section{ACCEPTED MANUSCRIPT}

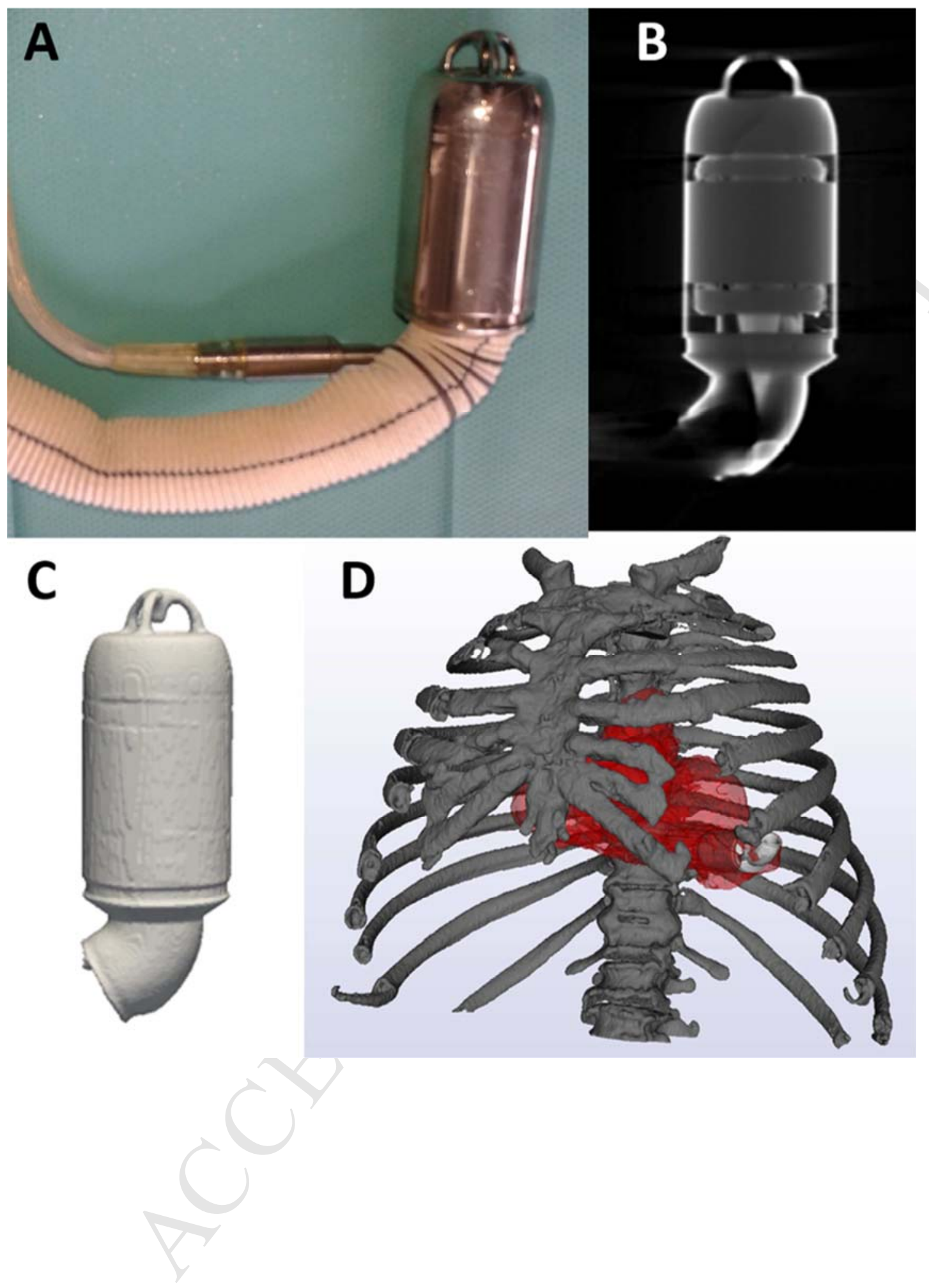




\section{ACCEPTED MANUSCRIPT}

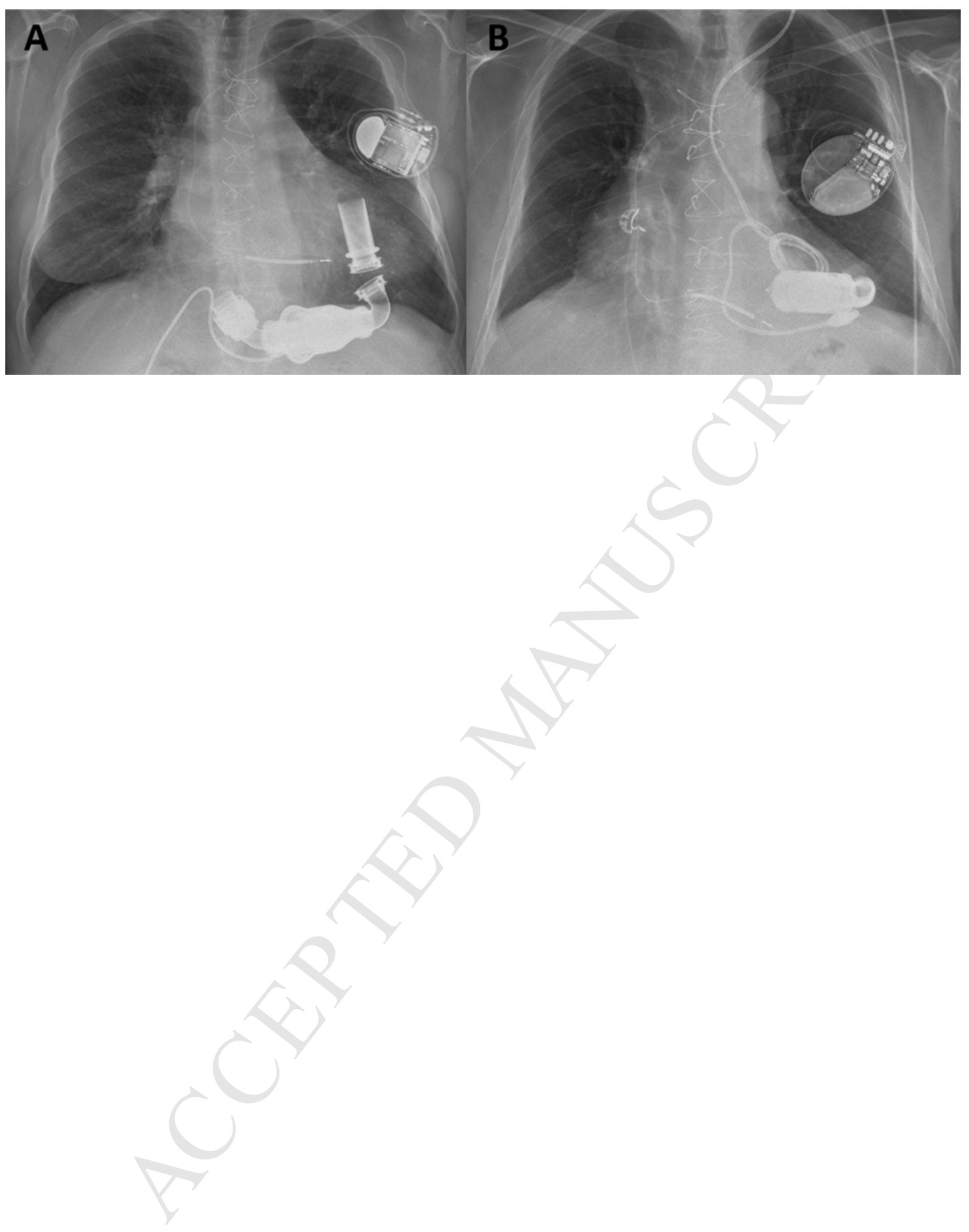

